\section{Unexpected venous diameter reduction by compression stocking of deep, but not of superficial veins}

\author{
Hugo Partsch,' Giovanni Mosti, 2 \\ Jean-Franois Uhl ${ }^{3}$ \\ 'Dermatology, Medical University of \\ Vienna, Austria; ${ }^{2}$ Angiology Department, \\ Clinica MD Barbantini, Lucca, Italy; \\ ${ }^{3}$ URDIA research unit - EA4465 - \\ University Paris Descartes, France
}

\section{Abstract}

Morphological studies on the effect of compression on the leg veins are rare and mostly performed in the supine position. The aim of this study was to investigate the influence of compression applied with different pressures on the venous calibre in the standing position. Standing magnetic resonance imaging was used to measure the venous diameters of superficial and deep leg veins in a patient with massive varicose veins without and with different levels of compression and realistic 3D vectorial models were built. In the standing position compression stockings with a pressure of $22 \mathrm{mmHg}$ were able to reduce the calibre of deep calf veins, but not of superficial varices. These were compressed only by bandages exerting pressures between 51 and 83 $\mathrm{mmHg}$. Compression stockings may reduce the diameter of deep calf veins in the standing position. To empty a varicose vein after venous ablation much higher pressures are required.

\section{Introduction}

Following the conventional concept compression devices will compress a leg vein when the external pressure is higher than the intravenous pressure. In the standing position of an adult person this intravenous pressure is around $80-100 \mathrm{mmHg}$ in a dorsal foot vein and around $60 \mathrm{mmHg}$ at knee level corresponding to the weight of the blood column between the right heart and the measuring point on the leg. Measurements of venous occlusion pressure by Duplex in connection with a sphygmomanometer containing a transparent window in different body positions were in agreement with this concept. ${ }^{1}$

The following observations demonstrate that superficial and deep veins may respond to compression in a different manner which has therapeutic consequences.

\section{Case Report}

A 42-year-old male presenting with massive varicose veins in connection with a dilated and completely incompetent great saphenous vein (C2EpAsPr) gave his consent to take part in a magnetic resonance imaging (MRI) investigation without contrast medium in the laboratory of Esaote, Genova, Italy. ${ }^{2}$ Using the G-scan ${ }^{\circledR}$ machine (Esaote, Genova) with a 0.25 Tesla field and a hydraulic tilting table transversal scans of the lower extremity were gained in supine and standing position, without compression, with a round knitted compression stocking (German compression class II, 23-32 mmHg at B) and after application of a moderate and a strong multi-component inelastic compression bandage (Rosidal sys ${ }^{\circledR}$, Lohmann \& Rauscher, Rengsdorf, Germany). The interface pressures of these compression devices were measured at mid-calf level in the supine and standing position using the Picopress ${ }^{\circledR}$ probe (Microlab Italia). ${ }^{3}$ In order to demonstrate that the venous diameter reductions observed under compression were not restricted to a small segmental slice only, a 3D-reconstruction using manual drawing of the T2 weighted slices and a computer software (Winsurf ${ }^{\circledR}$ ) was performed by JF Uhl and his team in Paris. ${ }^{4}$

Quantitative assessment of the results was done by planimetry of the venous cross-sections and by volume calculations in the 3D model.

The procedures were in accordance with the ethical standards of the responsible committee on human experimentation in Italy and with the Helsinki Declaration of 1975 (as revised in 2008).

\section{Results}

The pressures measured at mid-calf in supine/ standing position were $18 / 22 \mathrm{mmHg}$ under the stocking, $39 / 51 \mathrm{mmHg}$ under the first and 60/83 mmHg under the second bandage.

In the supine position (Figure 1A) large dilated varicose veins are seen (arrow), which collapse under a compression stocking exerting a pressure of $18 \mathrm{mmHg}$ (Figure 1B). At the same time the enlarged soleus vein and the deep leg veins are only slightly compressed.

During standing (Figure 2A) superficial and deep veins are slightly larger than in the lying position, a compression stocking (22 $\mathrm{mmHg}$ ) closes the soleus veins and narrows the deep leg veins, while the diameter of the superficial varicose veins remains unchanged (Figure 2B).

This can also be shown in the 3D-recon-
Correspondence: Hugo Partsch, Steinhäusl 126 , Altlengbach, 3033 Austria.

Tel. +43.664.1437.274

E-mail: hugo.partsch@meduniwien.ac.at

Key words: compression, magnetic resonance imaging, varicose veins, stockings, bandages.

Acknowledgements: we would like to thank Dr. E. Fracchia, Genova, for sending the patient. The research was carried out at the MRI research laboratory of Esaote, Genova, Italy and at the URDIA research unit of the University Paris Descartes, France.

Contributions: HP, outcome analysis, manuscript writing; GM, MRI (in the standing position) performing, manuscript writing; J-FU, 3D reconstruction and quantitative evaluation, manuscript writing.

Conflict of interests: the authors declare no potential conflict of interests.

Received for publication: 11 March 2012

Revision received: 21 May 2012.

Accepted for publication: 31 May 2012.

This work is licensed under a Creative Commons Attribution 3.0 License (by-nc 3.0).

(C) Copyright H. Partsch et al., 2012

Licensee PAGEPress, Italy

Veins and Lymphatics 2012; 1:e3

doi:10.4081/vl.2012.e3

struction (Figure 3, A without and B with the stocking). Quantitative volumetric results are demonstrated in Figure 4 in absolute terms (A) and in percent changes (B). It is clearly shown that the most intense compression effect involves the deep veins while the superficial veins stay nearly untouched.

Only a strong compression with a pressure of $51 \mathrm{mmHg}$ using an inelastic bandage leads to a narrowing not only of the deep but also of the superficial veins (Figure $5 \mathrm{~A}$ ). Under a pressure of $83 \mathrm{mmHg}$ in standing, both, superficial and deep veins are totally compressed (Figure 5B).

\section{Discussion}

This case is reported because of the instructive documentation obtained by MRI in the standing position in a patient with large varicose veins. Three normal individuals without varicose veins showed a similar pattern, especially concerning non-compressibility of the superficial veins by compression stockings during standing.

Compression of the leg leads to a shift of the muscle compartments which can clearly be 
seen by the change of the configuration of the MRI cross-section, especially in the standing position. This happens already with low pressure as demonstrated in Figure 2 and is obviously associated with an occlusion of the enlarged soleus vein and with considerable narrowing of the deep veins. In contrary the superficial varicose veins do not change its calibre. Using MRI in the lying position Downie et al. reported a greater cross-sectional area reduction under compression stockings in the deep veins (64\%) than in superficial veins (39\%). ${ }^{5}$ Analyzing our own data with MRI we found this surprising feature in the prone and in the standing position, but not in the supine position. ${ }^{2}$ Actually Downie's investigations were done in the prone position.

The described narrowing of deep veins in the standing and prone position, but not in the supine position points to the fact that the configuration of the muscle compartments which change in every body position plays a major role on the embedded veins. As visible result of these compartment-shifts the contour of the cross-section through the leg is getting more circular with in comparison without compression (Figures $2 \mathrm{~B}$ and $5 \mathrm{~B}$ versus Figures $2 \mathrm{~A}$ and $5 \mathrm{~A}$ ).

To narrow or to occlude superficial varicose veins in the standing position much higher pressures are needed as demonstrated in Figure 5. The same was demonstrated on superficial veins of three healthy individuals by MRI, in agreement with previous Duplex findings on individuals without varicose veins. $^{1}$

The fact that superficial leg veins are barely compressed by compression stockings in the upright position has practical implications. If we want to achieve an empty vein after any ablative intervention of varicose veins, e.g. after sclerotherapy, endovenous treatment or surgery, much higher pressure is needed in the ambulant patient than that exerted by a compression stocking. This is the most likely explanation that some authors using compression stockings with a pressure below $20 \mathrm{mmHg}$ were unable to demonstrate any benefit after sclerotherapy ${ }^{6}$ or after surgery ${ }^{7}$ while others using very strong bandages ${ }^{8}$ or eccentric compression pads in order to increase local pressure ${ }^{9-12}$ showed a much better outcome, especially concerning pain and haematoma-formation.

\section{Conclusions}

At the time being MRI in the lying and standing position with and without compression is certainly the best method to demonstrate diameter reductions in clearly defined veins of the lower extremity.

This short report using MRI in the standing position showed surprisingly stronger com-

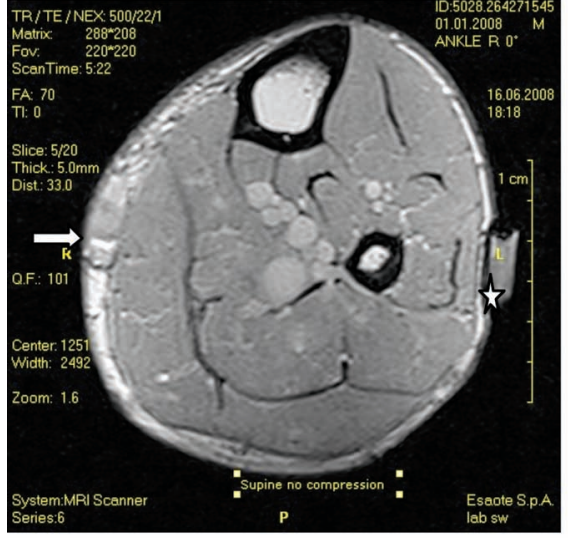

A

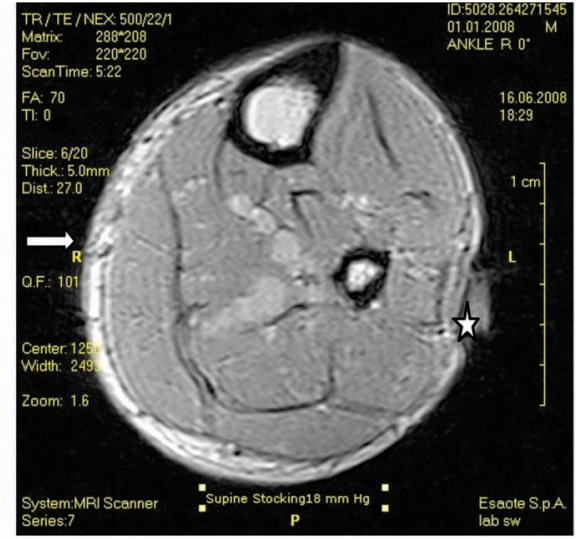

$\mathrm{B}$

Figure 1. A) Magnetic resonance imaging cross - section at mid-calf level in the supine position without compression. B) The same with compression stocking (18 $\mathrm{mmHg})$. The arrows point to the enlarged varicose veins on the medial lower leg. Opposite are the markers attached to the skin in order to evaluate identical segments
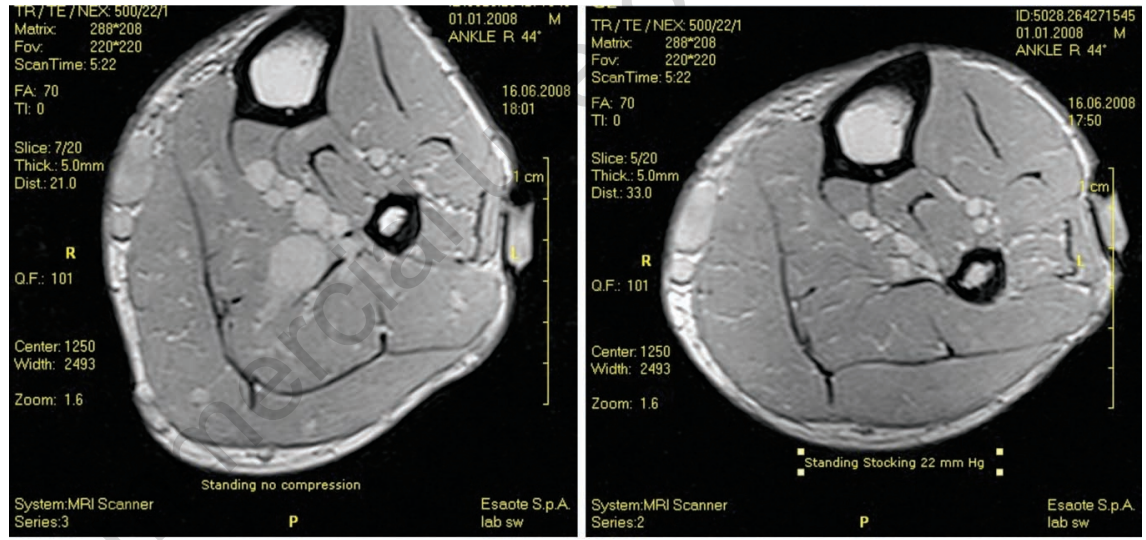

B

Figure 2. A, B) Same arrangement as in Figure 1, standing position.
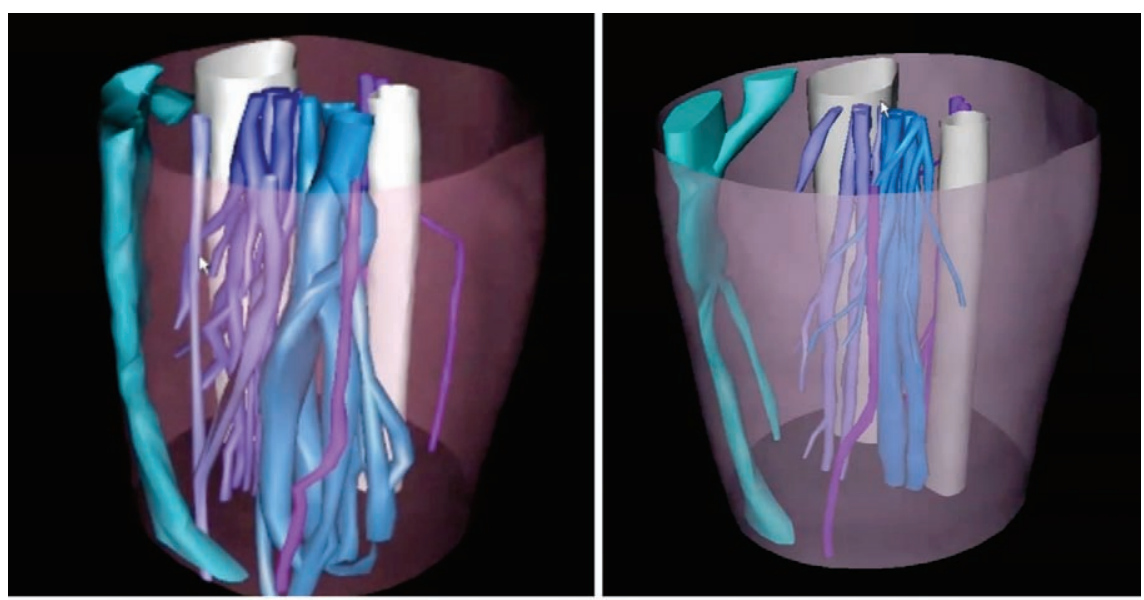

A B

Figure 3. A) $3 \mathrm{D}$ reconstruction in the standing position without compression. B) With compression stocking, reducing the calibre of the deep, but not of the superficial veins. 


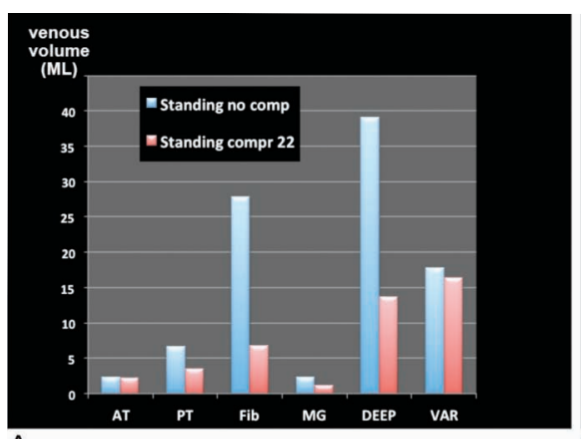

A

Figure 4. A) Calculation of vein volume. B) Its percent changes under the stocking based on the $3 \mathrm{D}$ reconstruction. AT, anterior tibial vein; PT, posterior tibial vein; Fib, fibular vein; MG, medial gastrocnemius vein; VAR, superficial varicose vein.

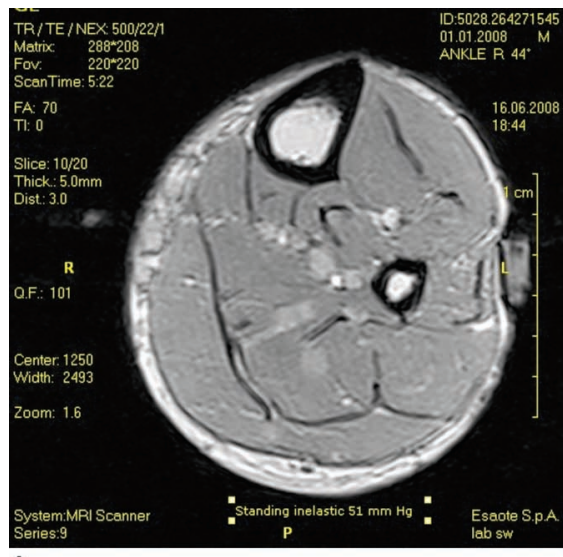

A

Figure 5. A) Standing position with inelastic bandage exerting $51 \mathrm{mmHg}$. B) Standing with very strong inelastic bandage (pressure $83 \mathrm{mmHg}$ ). pression effects on the deep than on superficial veins. This is in complete contrast to the traditional concept that compression would affect more the superficial than the deep veins.

To narrow superficial varicose leg-veins in the upright position in the demonstrated case (e.g. after endovenous procedures) a pressure of more than $50 \mathrm{mmHg}$ would be needed.

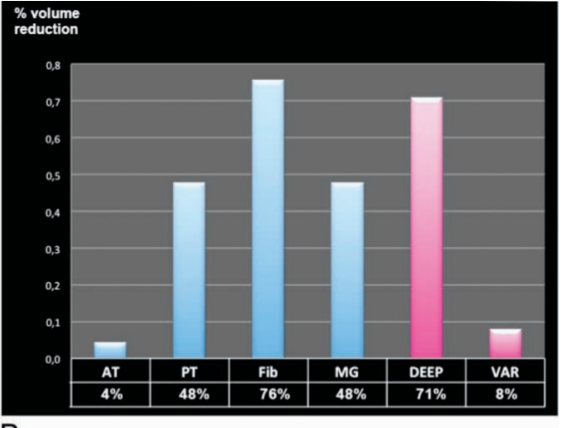

B

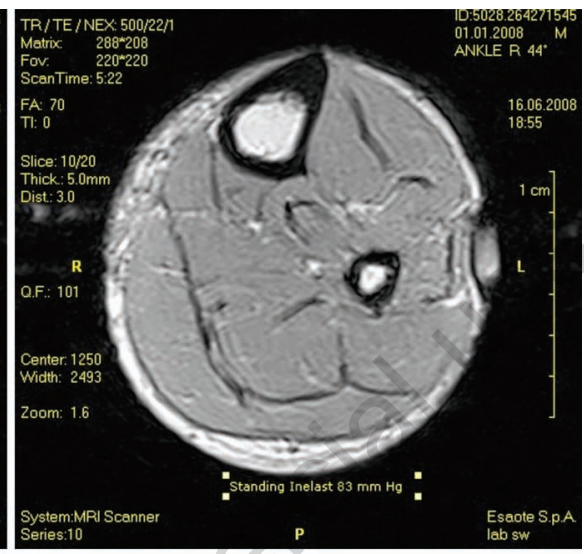

B bsw leg veins under compression demonstrated by magnetic resonance imaging (MRI). Int Angiol 2010;29:408-10.

3. Partsch H, Mosti G. Comparison of three portable instruments to measure compression pressure. Int Angiol 2010;29:426-30.

4. Uhl JF. 3D multislice CT to demonstrate the effects of compression therapy. Int Angiol 2010;29:411-5.

5. Downie SP, Firmin DN, Wood NB, et al. Role of MRI in investigating the effects of elastic compression stockings on the deformation of the superficial and deep veins in the lower leg. J Magn Imaging 2007;26:80-5.

6. Hamel-Desnos CM, Guias BJ, Desnos PR, Mesgard A. Foam sclerotherapy of the saphenous veins: randomised controlled trial with or without compression. Eur J Vasc Endovasc Surg 2010;39:500-7.

7. Biswas S, Clark A, Shields DA. Randomised clinical trial of the duration of compression therapy after varicose vein surgery. Eur J Vasc Endovasc Surg 2007:33:631-7.

8. Mosti G, Mattaliano V, Arleo S, Partsch H. Thigh compression after great saphenous surgery is more effective with high pressure. Int Angiol 2009;28:274-80.

9. Lugli M, Cogo A, Guerzoni S, et al. Effects of eccentric compression by a crossed-tape technique after endovenous laser ablation of the great saphenous vein: a randomized study. Phlebology 2009;24:151-6.

10. Benigni JP. Interface pressure measurements at the thigh under eccentric compression (Mediven Post Op Kit). Int Angiol 2009;28:334-5.

11. Benigni JP, Allaert FA, Desoutter P, et al. The efficiency of pain control using a thigh pad under the elastic stocking in patients following venous stripping: results of a case-control study. Perspect Vasc Surg Endovasc Ther 2011;23:23843.

12. Partsch B, Partsch H. Which pressure do we need to compress the great saphenous vein on the thigh? Dermatol Surg 2008;34: 1726-8.
1. Partsch B, Partsch H. Calf compression pressure required to achieve venous closure from supine to standing positions. J Vasc Surg 2005;42:734-8.

2. Partsch H, Mosti G, Mosti F. Narrowing of 